\title{
Targeting one of its own: expanding roles of substrates of the Legionella pneumophila Dot/lcm type IV secretion system
}

\author{
Zhao-Qing Luo* \\ Department of Biological Sciences, Purdue University, West Lafayette, IN, USA \\ *Correspondence: luoz@purdue.edu
}

Facing the many host defense mechanisms at different stages of the infection, a pathogen needs to employ corresponding arsenals either to hijack host cellular processes for its own use or to thwart the attacks from the host. For numerous bacterial pathogens, one of the effective weapons is effector protein. Type IV protein secretion systems are associated with the virulence of many important pathogens such as Helicobacter pylori, Bartenella pertussis, Brucella spp., Coxiella burnetii, and Legionella pneumophila (Backert and Meyer, 2006). Although the structures of these transporters appear similar, their protein substrates differ drastically not only in functions but also in abundance. For example, despite extensive efforts, CagA is the only effector identified for the Cag system of H. pylori (Hatakeyama, 2008). On the other hand, there are at least 274 experimentally confirmed protein substrates of the L. pneumophila Dot/Icm system (Zhu et al., 2011). This count is close to $10 \%$ of the predicted genes in the L. pneumophila genome (Cazalet et al., 2004; Chien et al., 2004; Schroeder et al., 2010), making the Dot/Icm system arguably the most prolific protein transporter in term of the number of translocated substrates. Similar to effectors of other types of secretion systems, Dot/Icm substrates function to target various host cellular processes, such as vesicle trafficking, cell death, ubiquitination, lipid metabolism, and innate immunity, thus allowing the biogenesis of an intracellular niche permissive for bacterial replication (Isberg et al., 2009; Hubber and Roy, 2010).

To cope with the dynamic response from the host, bacterial pathogens can employ several strategies to achieve temporal regulation of the activity of their virulence factors. The most commonly used mechanism is to regulate expression of virulence factors at the transcriptional level in response to environmental cues present during different phases of infection. For example, many Legionella effector genes are induced when bacteria enter the post-exponential phase and are ready to infect (Bruggemann et al., 2006). The second is to control the translocation efficiency of effectors at posttranslational level, which is exemplified by small RNA-mediated regulation of effector transfer in Salmonella typhimurium (Padalon-Brauch et al., 2008). The third is to code for effectors capable of causing opposite cell biological effects to neutralize or reverse the effects caused by other effectors. In S. typhimurium, bacterial entry is induced by SopE, a guanine nucleotide exchange factor (GEF) for the Rho family of small GTPases, an activity that is antagonized by the GTPase activation protein (GAP) SopE. In this scenario, temporal control is achieved by the inherent differences in the sensitivity of these two proteins to host proteasome degradation (Kubori and Galan, 2003). Similarly, L. pneumophila reverses the SidM/DrrA-mediated activation of the small GTPase Rab1 by the GAP protein LepB (Ingmundson et al., 2007). However, the mechanism underlying the temporal control remains elusive. Third, the pathogens can inhibit pathways triggered by themselves. For example, as a result of apoptosis induced by L. pneumophila challenge, infected cells contains active caspases 3 and 7 , but the activity of these enzymes presumably can be inhibited by IAPs induced by the bacterium itself (Abu-Zant et al., 2005, 2007; Losick and Isberg, 2006; Nogueira et al., 2009). Unfortunately, the bacterial proteins involved in such manipulation remain unknown as does the mechanism underlying the temporal regulation.

Almost all characterized virulence factors exert their effects by targeting one or more host molecules. The discovery by Kubori et al. (2010) extended the roles of bacterial effectors into a completely new domain: direct regulation of the function of other effectors, in this particular case, by targeting a different effector protein for proteasome degradation. LubX is a U-box-type E3 ubiquitin ligase that was previously found to target the host kinase Clk1 (Kubori et al., 2008). In this new study, the authors reported that LubX polyubiquitinates the effector $\mathrm{SidH}$ and targets it for degradation (Kubori et al., 2010). Moreover, their data showed that in a fruit fly infection model, deletion of lubX caused a hyper-lethality phenotype and reduced bacterial replication. Thus, this discovery established a new mechanism used by a bacterial pathogen to temporally control the activity of its virulence factors. Their results also substantiated some earlier observations on L. pneumophila infection. First, they showed that LubX is expressed and translocated by the Dot/Icm system only until after the initial phase of infection has been established, peaking at $10 \mathrm{~h}$ post infection (Kubori et al., 2008, 2010), which is in line with the observation that the Dot $/ \mathrm{Icm}$ system is active for at least $8 \mathrm{~h}$ after bacterial internalization (Liu et al., 2008). Second, targeting of SidH did not occur in the initial phase of infection, implying that SidH is important in the early phase of infection and becomes unnecessary or even detrimental to further development of the bacterial phagosome as infection proceeds. Such prediction is consistent with the potential role of SidH in inhibition of host cell death (Laguna et al., 2006), because continued arrest of apoptosis presumably is counterproductive when the infection comes to a close.

This study also provided an explanation to one of the perplexing questions in the study of $L$. pneumophila pathogenesis: Why does this bacterium code for so many effectors? At least two models can be used to explain this phenomenon. The first is that there is a tremendous functional redundancy among effectors targeting a particular host cellular process. This model is supported by the fact that mutations eliminating one single effector gene rarely caused defects in intracellular bacterial growth (Ensminger and Isberg, 2009). Second, these effectors 
may be necessary for successful colonization of the taxonomically diverse protozoan hosts encountered by L. pneumophila in the environment. The study by Nagai and colleagues added a novel dimension of targets regulated by L. pneumophila virulence factors.

Given the complexity of the interactions between L. pneumophila and its hosts, it will not be surprising to identify more metaeffectors with modes of action different from that of LubX in future study. It is possible that inhibition of effector activity by a second effector can be achieved by posttranslational modifications. An effector can directly reverse the modification made by another effector on its target molecule. For example, such regulation conceivably can be achieved by a pair of effectors with kinase and phosphatase activity, respectively. Alternatively, one effector can directly modify another effector at post-translational level to activate or inactivate its function. As novel post-translational modifications such as AMPylation (Roy and Mukherjee, 2009; Muller et al., 2010) and farnesylation (Ivanov et al., 2010; Price et al., 2010) continued to be identified in Legionella effectors, it will be interesting to know whether these modifications are subjected to effector-mediated regulation. Although the existence of these regulatory mechanisms in the control of L. pneumophila effector activity is uncertain, it is certain that more excitement will be generated in our continuing study of these several hundreds interesting proteins.

\section{ACKNOWLEDGMENTS}

I thank members of my laboratory for helpful discussion. I am grateful for the grant support from the National Institutes of Health (NIH; R01AI069344, K02AI085403 and R21AI092043, and R56AI090142).

\section{REFERENCES}

Abu-Zant, A., Jones, S., Asare, R., Suttles, J., Price, C., Graham, J., and Kwaik, Y. A. (2007). Anti-apoptotic signalling by the Dot/Icm secretion system of L. pneumophila. Cell. Microbiol. 9, 246-264.

Abu-Zant, A., Santic, M., Molmeret, M., Jones, S., Helbig, J., and Abu Kwaik, Y. (2005). Incomplete activation of macrophage apoptosis during intracellular replication of Legionella pneumophila. Infect. Immun. 73 , 5339-5349.
Backert, S., and Meyer, T. F. (2006). Type IV secretion systems and their effectors in bacterial pathogenesis. Curr. Opin. Microbiol. 9, 207-217.

Bruggemann, H., Hagman, A., Jules, M., Sismeiro, O., Dillies, M. A., Gouyette, C., Kunst, F., Steinert, M., Heuner, K., Coppee, J. Y., and Buchrieser, C. (2006). Virulence strategies for infecting phagocytes deduced from the in vivo transcriptional program of Legionella pneumophila. Cell. Microbiol. 8, 1228-1240.

Cazalet, C., Rusniok, C., Bruggemann, H., Zidane, N. Magnier, A., Ma, L., Tichit, M., Jarraud, S., Bouchier, C., Vandenesch, F., Kunst, F., Etienne, J., Glaser, P. and Buchrieser, C. (2004). Evidence in the Legionella pneumophila genome for exploitation of host cell functions and high genome plasticity. Nat. Genet. 36, 1165-1173.

Chien, M., Morozova, I., Shi, S., Sheng, H., Chen, J., Gomez, S. M., Asamani, G., Hill, K., Nuara, J., Feder, M., Rineer, J., Greenberg, J. J., Steshenko, V., Park, S. H., Zhao, B., Teplitskaya, E., Edwards, J. R., Pampou, S., Georghiou, A., Chou, I. C., Iannuccilli, W., Ulz, M. E., Kim, D. H., Geringer-Sameth, A., Goldsberry, C., Morozov, P., Fischer, S. G., Segal, G., Qu, X., Rzhetsky, A., Zhang, P., Cayanis, E., De Jong, P. J., Ju, J., Kalachikov, S., Shuman, H. A., and Russo, J. J. (2004). The genomic sequence of the accidental pathogen Legionella pneumophila. Science 305, 1966-1968.

Ensminger, A. W., and Isberg, R. R. (2009). Legionella pneumophila Dot/Icm translocated substrates: a sum of parts. Curr. Opin. Microbiol. 12, 67-73.

Hatakeyama, M. (2008). SagA of CagA in Helicobacter pylori pathogenesis. Curr. Opin. Microbiol. 11 , 30-37.

Hubber, A., and Roy, C. R. (2010). Modulation of host cell function by Legionella pneumophila type IV effectors. Annu. Rev. Cell Dev. Biol. 26, 261-283.

Ingmundson, A., Delprato, A., Lambright, D. G., and Roy, C. R. (2007). Legionella pneumophila proteins that regulate Rab1 membrane cycling. Nature 450, 365-369.

Isberg, R. R., O'Connor, T. J., and Heidtman, M. (2009). The Legionella pneumophila replication vacuole: making a cosy niche inside host cells. Nat. Rev. Microbiol. 7, 13-24.

Ivanov, S. S., Charron, G., Hang, H. C., and Roy, C. R. (2010). Lipidation by the host prenyltransferase machinery facilitates membrane localization of Legionella pneumophila effector proteins. J. Biol. Chem. 285, 34686-34698.

Kubori, T., and Galan, J. E. (2003). Temporal regulation of Salmonella virulence effector function by proteasomedependent protein degradation. Cell 115, 333-342.

Kubori, T., Hyakutake, A., and Nagai, H. (2008). Legionella translocates an E3 ubiquitin ligase that has multiple U-boxes with distinct functions. Mol. Microbiol. 67 1307-1319.

Kubori, T., Shinzawa, N., Kanuka,H., and Nagai,H. (2010). Legionella metaeffector exploits host proteasome to temporally regulate cognate effector. PLoS Pathog. 6 , e1001216. doi: 10.1371/journal.ppat.1001216

Laguna, R. K., Creasey, E. A., Li, Z., Valtz, N., and Isberg, R. R. (2006). A Legionella pneumophila-translocated substrate that is required for growth within macrophages and protection from host cell death. Proc. Natl. Acad. Sci. U.S.A. 103, 18745-18750.

Liu, Y., Gao, P., Banga, S., and Luo, Z. Q. (2008). An in vivo gene deletion system for determining temporal requirement of bacterial virulence factors. Proc. Natl. Acad. Sci. U.S.A. 105, 9385-9390.

Losick, V. P., and Isberg, R. R. (2006). NF-kappaB translocation prevents host cell death after low-dose challenge by Legionella pneumophila. J. Exp. Med. 203, 2177-2189.

Muller, M. P., Peters, H., Blumer, J., Blankenfeldt, W., Goody, R. S., and Itzen, A. (2010). The Legionella effector protein DrrA AMPylates the membrane traffic regulator Rablb. Science 329, 946-949.

Nogueira, C. V., Lindsten, T., Jamieson, A. M., Case, C. L., Shin, S., Thompson, C. B., and Roy, C. R. (2009). Rapid pathogen-induced apoptosis: a mechanism used by dendritic cells to limit intracellular replication of Legionella pneumophila. PLoS Pathog. 5, e1000478. doi: 10.1371/journal.ppat.1000478

Padalon-Brauch, G., Hershberg, R., Elgrably-Weiss, M., Baruch, K., Rosenshine, I., Margalit, H., and Altuvia, S. (2008). Small RNAs encoded within genetic islands of Salmonella typhimurium show host-induced expression and role in virulence. Nucleic Acids Res. 36, 1913-1927.

Price, C. T., Al-Quadan, T., Santic, M., Jones, S. C., and Abu Kwaik, Y. (2010). Exploitation of conserved eukaryotic host cell farnesylation machinery by an F-box effector of Legionella pneumophila. J. Exp. Med. 207, 1713-1726.

Roy, C. R., and Mukherjee, S. (2009). Bacterial FIC proteins AMP up infection. Sci. Signal. 2, pe14.

Schroeder, G. N., Petty, N. K., Mousnier, A., Harding, C. R., Vogrin, A. J., Wee, B., Fry, N. K., Harrison, T. G., Newton, H. J., Thomson, N. R., Beatson, S.A., Dougan, G., Hartland, E. L., and Frankel, G. (2010). Legionella pneumophila strain $130 \mathrm{~b}$ possesses a unique combination of type IV secretion systems and novel Dot/ Icm secretion system effector proteins. J. Bacteriol. 192, 6001-6016.

Zhu, W., Banga, S., Tan, Y., Zheng, C., Stephenson, R., Gately, J., and Luo, Z.-Q. (2011). Comprehensive identification of protein substrates of the Dot/Icm type IV transporter of Legionella pneumophila. PLoS ONE. (in press)

Received: 21 January 2011; accepted: 05 February 2011; published online: 15 February 2011.

Citation: Luo Z-Q (2011) Targeting one of its own: expanding roles of substrates of the Legionella pneumophila Dot/ Icm type IV secretion system. Front. Microbio. 2:31. doi: 10.3389/fmicb.2011.00031

This article was submitted to Frontiers in Cellular and Infection Microbiology, a specialty of Frontiers in Microbiology.

Copyright (c) 2011 Luo. This is an open-access article subject to an exclusive license agreement between the authors and Frontiers Media SA, which permits unrestricted use, distribution, and reproduction in any medium, provided the original authors and source are credited. 